\title{
EDUCAÇÃO AMBIENTAL EM UNIDADES DE CONSERVAÇÃO: 0 CASO DA ÁREA DE PROTEÇÃO MORRO DO URUBU
}

\author{
Marta Aline Santos ${ }^{1}$ \\ Sofia Cerqueira Schettino ${ }^{2}$ \\ Isis Annielli da Hora Bastos ${ }^{3}$
}

\begin{abstract}
Resumo
As Unidades de Conservação da Natureza são instrumentos legais pelos quais a biodiversidade pode ser protegida. Entretanto, as Unidades de Conservação de todo o Brasil não conseguem atingir seus objetivos e sofrem com ações antrópicas. Para minimizar os impactos negativos das ações antrópicas nestas áreas, a Educação Ambiental tem sido muito utilizada ou vista como uma solução. A Área de Proteção Ambiental Morro do Urubu, localizada no município de Aracaju, Sergipe, apresenta inúmeras dificuldades de fazer valer seus objetivos de conservação dos seus recursos naturais, mas estas dificuldades são potencializadas por inserir-se no ambiente urbano. O presente trabalho apresenta um levantamento sobre as ações de Educação Ambiental que são realizadas na APA Morro do Urubu. A metodologia utilizada seguiu os seguintes passos: pesquisa bibliográfica; elaboração e aplicação de questionário não probabilistico, análise não probabilistica dos dados e conclusões. A partir da pesquisa realizada, observou-se que várias instituições tem promovido e aplicado a Educação Ambiental em suas diferentes abordagens na APA Morro do Urubu, com o intuito de diminuir o problema socioambiental porém estas não atigem resultados satisfatórios. Conclui-se que as Ações de Educação Ambiental na APA Morro do Urubu estão presentes mas ainda são incipientes, pois observou-se que o maior foco dessas ações é o Parque da Cidade, local esse inserido na APA, sendo que sua área engloba uma grande população que vai além dos aredores do Parque, e que também necessita ser sensibilizada quanto à questão ambiental na qual estão inseridas.
\end{abstract}

Palavras-chave: Unidades de Conservação; APA Morro do Urubu; Educação Ambiental.

\footnotetext{
Abstract

The Nature Conservation Units are legal instruments by which biodiversity can be protected. However, the protected areas throughout Brazil fail to achieve their goals and suffer from human actions. To minimize the negative impacts of human activities in these fields, environmental education has been widely used or viewed as a solution. The Environmental Protection Area Buzzard Hill, located in the city of Aracaju, Sergipe, Brazil, presents many difficulties to enforce its objectives of conservation of its natural resources, but these difficulties are enhanced by inserting in the urban environment. This paper presents a survey on Environmental Education actions that are performed in APA hill Buzzard. The methodology involved the following steps: literature research, development 
and application of a questionnaire is not probabilistic, non probabilistic analysis of the data and conclusions. From the survey, it was observed that several institutions have promoted and applied environmental education in its different approaches in Hill APA's Buzzard, with the aim of reducing the environmental problem but these do not reach satisfactory results. It was concluded that the Shares Environmental Education in APA Hill Buzzard are present but are still tentative, since it was observed that the major focus of these actions is the City Park, this location entered in APA, and its area encompasses a large population that goes beyond the vicinity Park's, and also need to be sensitized about the environmental issue in which they are embedded.

Keywords: Conservation Units; APA Hill Buzzard; Environmental Education. 


\section{I - Introdução}

As discussões sobre a questão ambiental tem alcançado maior repercursão e se tornaram presentes no cotidiano da sociedade brasileira diante das crises ambientais e consequentes ameaças à biodiversidade. Para proteger o meio ambiente dessas crises e priorizar a proteção à biodiversidade foi instituído no Brasil, um sistema de áreas naturais protegidas, denominadas Unidades de Conservação, que tem sido implantadas com o objetivo principal de resguardar ao máximo a diversidade dos ecossistemas e espécies existentes (TORRES, 2008).

Segundo o Sistema Nacional de Unidades de Conservação instituído pela Lei no 9.985/2000, define Unidades de Conservação como:

São espaços territoriais e seus recursos ambientais, incluindo as águas jurisdicionais com características naturais relevantes, legalmente instituídos pelo poder público, com objetivos de conservação, ao qual se aplicam garantias adequadas de proteção.

No Brasil, existe um grande número de Unidades de Conservação em vista da sua grande diversidade biológica e seus ecossistemas. Entretanto, a simples criação de Unidades de Conservação não garante que esta verdadeiramente cumpram seus objetivos de conservação, sendo necessário o estabelecimento de estratégias que promovam a conservação dos ambientes naturais. Nesse aspecto, cabe ressaltar o atual interesse por envolver as comunidades locais em esforços conservacionistas (DALLE e POTVIN, 2004). Uma forma eficaz de envolver as comunidades na preservação ambiental em Unidades de Conservação passa pela Educação, mais especificamente pela Educação Ambiental e consequentemente pela Sustentabilidade das atividades humanas.

\section{Histórico da Educação Ambiental}

Nas últimas décadas, intensificaram-se as preocupações inerentes à temática ambiental a as iniciativas dos variados setores da sociedade para o desenvolvimento de atividades e projetos no intuito de educar as comunidades, sensibilizá-las para as questões ambientais e mobilizá-las para a adoção de posturas benéficas ao equilíbrio ambiental.

$\mathrm{O}$ aumento de interesse mundial com o meio ambiente começou em meados do século passado, com os avanços científicos sobre as dinâmicas dos ecossistemas; a ocorrência de acidentes ambientais; a crise energética e a conquista de espaços políticos pelos movimentos ambientalistas. O que motivo a Organização das Nações Unidas (ONU) discutisse que precisava-se definir metas de desenvolvimento social. Para tanto, foi considerado a Educação Ambiental como um dos meios principais para esse desenvolvimento (IBASE, 2006).

A primeira vez que se usou o termo Educação Ambiental foi na Universidade de Keele, no Reino Unido em 1965. Somente em 1975, foi feito algo mais elaborado a respeito da Educação Ambiental, com a realização do $1^{\text {o }}$ Seminário Internacional de Educação Ambiental, em 
Belgrado (antiga Ioguslávia). Esse foi um dos desdobramentos das discussões da Conferência das Nações Unidas sobre o Ambiente Humano, na qual foi acordado pela recomendação 96, principio 19, a necessidade de se inserir a discussão acerca do meio ambiente na educação (UNESCO, 1976 in IBASE, 2006).

A grande Conferência Internacional da Organização das Nações Unidas sobre Educação Ambiental foi realizada em Tiblisi (Geórgia na ex União Soviética), em 1977. Essa conferência foi um grande marco e é considerada até hoje, para as nações do planeta como a principal a respeito. Em Tiblisi, vários itens metodológicos tidos como co-dependentes e integrados, foram listados como parte de uma educação que seria coerente com o novo tipo de desenvolvimento social.

Segundo BUSTOS (2003) a Educação Ambiental foi se fortalecendo com o passar dos anos, pois em 1987, a UNESCO e o PNUMA organizaram o $2^{\circ}$ Congresso Internacional de treinamento e Educação Ambiental em Moscou, conhecido como "Tiblisi mais dez". Ainda em 1987, foi concluído o Relatório da Comissão Brundtland, intitulado "Nosso Futuro Comum”, através desse relatório o termo Desenvolvimento Sustentável foi consagrado mundialmente. Concernente ao desenvolvimento sustentável REIGOTA (1995), afirma que a Educação Ambiental é de fundamental importância para a produção e economia do mundo.

Em 1992, realizou-se a 2a Conferencia das Nações Unidas sobre o Meio Ambiente e Desenvolvimento (UNCED), conhecida como a Rio-92. O enfoque principal desta conferência foi a busca de uma estratégia internacional, visando um modelo de gestão ecologicamente racional dos recursos e a preservação da vida (BUSTOS, 2003). No campo da Educação Ambiental, foi proposto um modelo educacional que estivesse voltado à problemática ambiental e aos aspectos peculiares ao meio ambiente no qual estivesse inserida a comunidade, e consequentemente ao Desenvolvimento Sustentável, visando a conservação dos recursos naturais para garanti-los às gerações futuras. Nessa conferência foi elaborado um documento composto de 40 capítulos intitulado 'Agenda 21', nesse documento também foi dada atenção a Educação Ambiental no seu capítulo 36 intitulado 'Promovendo a Conscientização Ambiental.

\section{Educação Ambiental em Unidades de Conservação}

A Educação Ambiental é imprescindível para os processos de sensibilização da sociedade como um todo. De modo que no Brasil existe uma lei especifica que institui a Política Nacional da Educação Ambiental, é a lei no 9795 de 27 de Abril de 1999, que define a Educação Ambiental como:

Entende-seporeducação ambientalos processospormeiodos quais o indivíduo e a coletividade constroem valores sociais, conhecimentos, habilidades, atitudes e competências voltadas para a conservação do meio ambiente, bem de uso comum do povo, essencial a qualidade de vida e sustentabilidade.

Dentro deste contexto a Educação Ambiental é muito oportuna quando 
aplicada às Unidades de Conservação, pois o propósito inicial na criação de Unidades é a proteção da biodiversidade, para tanto esperava-se que essas áreas fossem livres de ação antrópica. No entanto, a maioria das Unidades de Conservação do Brasil tem sofrido pressão dos seus recursos naturais pela presença de comunidades tradicionais, visitação da população a essas áreas para recreação e também as comunidades que residem no entorno dessas unidades.

Essas populações supracitadas acabam por ameaçar a proteção da biodiversidade por não ter conhecimento de como poderiam proteger o ambiente em que vivem, portanto a Educação Ambiental assume um papel imprescindível, pois ela sensibiliza e acrescenta às comunidades novos hábitos ou mudanças de atividades para a promoção da conservação ecológica das Unidades de Conservação. Para FREY (2001), a intervenção do estado como facilitador do processo, estimula a participação das comunidades e fortalece a consciência ecológica.

Por esse motivo, vários grupos (instituições públicas) ealguma ongs tem se empenhado em desenvolver projetos de Educação Ambiental em Unidades de Conservação. Esse é o caso da Área de Proteção Ambiental Morro do Urubu, ela tem sofrido com a ação antrópica com as comunidades que residem na APA. Tem-se desenvolvido projetos de Educação Ambiental na APA por universidades e outros órgãos público, visando que tais comunidades promovam a sustentabilidade nesta Unidade de Conservação.

\section{Educação Ambiental e suas abordagens}

A Educação Ambiental (EA) pode ser abordada de diferentes maneiras. As diferentes abordagens são: a crítica, a emancipatória ou transformadora, a ecopedagogia, a educação no processo de gestão ambiental e também a alfabetização ecológica. Tais abordagens, apesar de diferentes quando aplicadas são muito benéficas não somente ao meio ambiente, mas também às comunidades envolvidas.

A EA Emancipatória pretende, ampliar os espaços de liberdade de indivíduos e grupos que dela participam, transformando as situações de dominação e sujeição a que estão submetidos através da tomada de consciência de seu lugar no mundo, de seus direitos e de seu potencial para recriar as relações que estabelecem consigo, com os outros em sociedade e com o ambiente circundante (LIMA, 2004).

Outra abordagem interessante é a Alfabetização Ecológica que consiste no conhecimento, internalização eimplementação de princípios ecológicos nas comunidades humanas: Interdependência, Cooperação e Parceria, Coevolução, Flexibilidade, Diversidade, Reciclagem e ciclos ecológicos (MUNHOZ, 2004). Munhoz (2004) utilizou a Alfabetização Ecológica na concepção de projetos de educação ambiental para empresas, para odesenvolvimento deliderançasjovens na campanha doconsumo consciente.

A EA Crítica objetiva promover ambientes educativos de mobilização dos processos de intervenção sobre a realidade e seus problemas socioambientais, para que sejam superados nestes ambientes as armadilhas dos paradigmas atuais e propicia um processo educativo, em 
que neste exercício, educandos e educadores, se capacitam e contribuem, pelo exercício de uma cidadania ativa, na transformação da grave crise socioambiental (GUIMARÃES, 2004).

Comovisto nas descrições sobre as abordagens deEducação Ambiental observa-se que cada uma apresenta suas peculiaridades nas suas metodologias, mas sabe-se que todas as abordagens têm o mesmo objetivo que é promover a proteção ao meio ambiente.

Em vista dos benefícios da Educação Ambiental e suas diferentes abordagens, tem sido desenvolvidos projetos de Educação Ambiental em Unidades de Conservação. Esse é o caso das Unidades de Conservação de Sergipe onde tem sido desenvolvidas ações de Educação Ambiental em busca da sustentabilidade dessas áreas, por meio da sensibilização da comunidade.

\section{Área de Proteção Morro do Urubu}

A Área de Proteção Ambiental Morro do Urubu, é uma Unidade de Conservação localizada na área urbana de Aracaju/SE. Limita-se ao norte com rio do Sal, ao leste com o rio Sergipe e ao sul e oeste com as áreas urbanas da zona norte do município. Trata-se de uma região onde predominava originalmente a mata atlântica e seus ecossistemas associados, além de inclaves de cerrado (GOMES, 2006). A APA Morro do Urubu foi criada e regulamentada pelos decretos $\mathrm{n}^{\circ} 13.713$ de 16 de junho de 1993 e no 15.405 de 14 de julho de 1995. Nesta área, está inserido o Parque Estadual José Rollemberg Leite, popularmente conhecido como Parque da Cidade, onde se localiza o zoológico de Aracaju (PINTO, 2008). Segundo Gomes (2006) essa área vem sofrendo pressão urbana e cada vez mais se descaracterizando. Além disso, o complexo de vegetação encontra-se hoje bastante comprometido, sobretudo pela invasão, construção e urbanização de favelas na área.

Em se tratando de um problema socioambiental, as ocupações subnormais e seu conseqüente impacto ambiental constituem-se como reflexo de algumas camadas sociais de menorpoderaquisitivo,queocupamáreassemqualquertipodeinfra-estruturaurbana, ordenamento territorial ou mesmo a titularidade da área ocupada, constituindo dessa forma assentos subnormais conhecidos popularmente por favelas (MATOS, 2010).

Justamente por causa desses graves problemas ambientais que a APA Morro do Urubu tem enfrentado, são desenvolvidos trabalhos de Educação Ambiental com a população que reside na APA. Essas ações são de fundamental importância em busca da sustentabilidade nessa Unidade de Conservação.

Portanto,opresentetrabalhoapresentaasaçõesdeEducação Ambientalqueestãosendo desenvolvido pordiversasinstituiçõesnaÁreadeProteção AmbientalMorrodoUrubu.

\section{II - Metodologia da Pesquisa}


Para atingir o objetivo proposto o presente trabalho foi uma pesquisa qualitativa, de caráter exploratório e não probabilistico, utilizando o método do estudo de caso, tendo como instrumento de análise a aplicação de questionários. Assim foram seguidos os seguintes passos metodológicos.

\section{Levantamento de dados secundários}

Primeiramente foi realizada revisão bibliográfica e levantamento de dados secundários junto a instituições públicas sobre Unidades de Conservação e sua importância para a proteção da biodiversidade; sobre a área de estudo; e sobre a evolução da Educação ambiental, do seu princípio até os dias de hoje, enfatizando as diferentes abordagens e sua eficácia quando aplicada em Unidades de Conservação, para a sustentabilidade dessas áreas.

\section{Elaboração do questionário}

O questionário foi elaborado de maneira simples. Está estruturado com perguntas para pesquisa qualitativa, no qual o entrevistado tenha condições de respondê-las de maneira completa.

\section{Levantamento de dados primários}

Os dados primários foram coletados por meio de visitas realizadas à área e aos agentes diretamente envolvidos diretamente com a Educação Ambiental na Área de Proteção Ambiental Morro do Urubu, no segundo caso mediante aplicação de questionário. $\mathrm{O}$ critério para a seleção dos entrevistados leva em consideraçãoo maior envolvimento de instituições públicas na promoção da Educação Ambiental na APA Morro do Urubu.

\section{III - Resultados e discussões}

Apesar de abrigar o último remanescente de Mata Atlântica do município de Aracaju, o interesse do poder público para a preservação do Morro do Urubu deu-se a partir da década de 1970 (MATOS, 2010). Nesse ínterim, foram surgindo no que agora faz parte da APA Morro do Urubu um aglomerado de habitações, as quais nos últimos anos aumentou. Na figura 1 abaixo pode-se visualizar o bairro Porto Dantas, no qual esta localizada a já referida APA. 


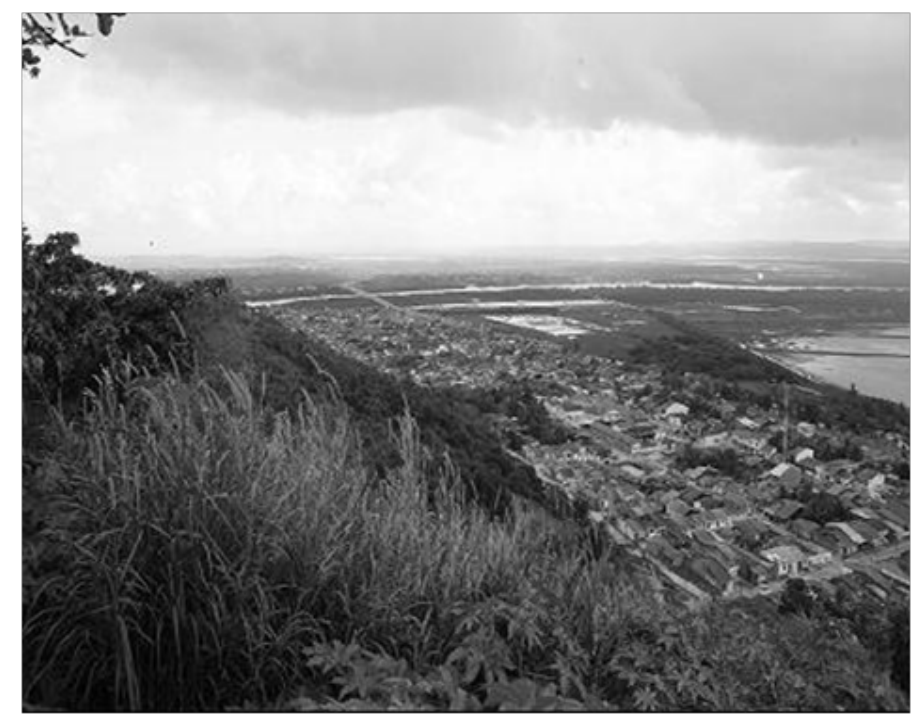

Figura 1 - Bairro Porto Dantas (Fonte: MATOS, 2010)

Dentro do bairro Porto Dantas a comunidade do Coqueiral confere maior preocupação, pois seu crescimento e a pressão exercida sobre o meio ambiente por suas atividades configura-se como muito negativa. Os impactos ambientais mais visíveis: o desmatamento, erosão devido ao desmatamento, efluentes domésticos dispostos inadequadamente, resíduos sólidos etc. Esses impactos podem ser visualizados a seguir nas figuras 2 respectivamente.
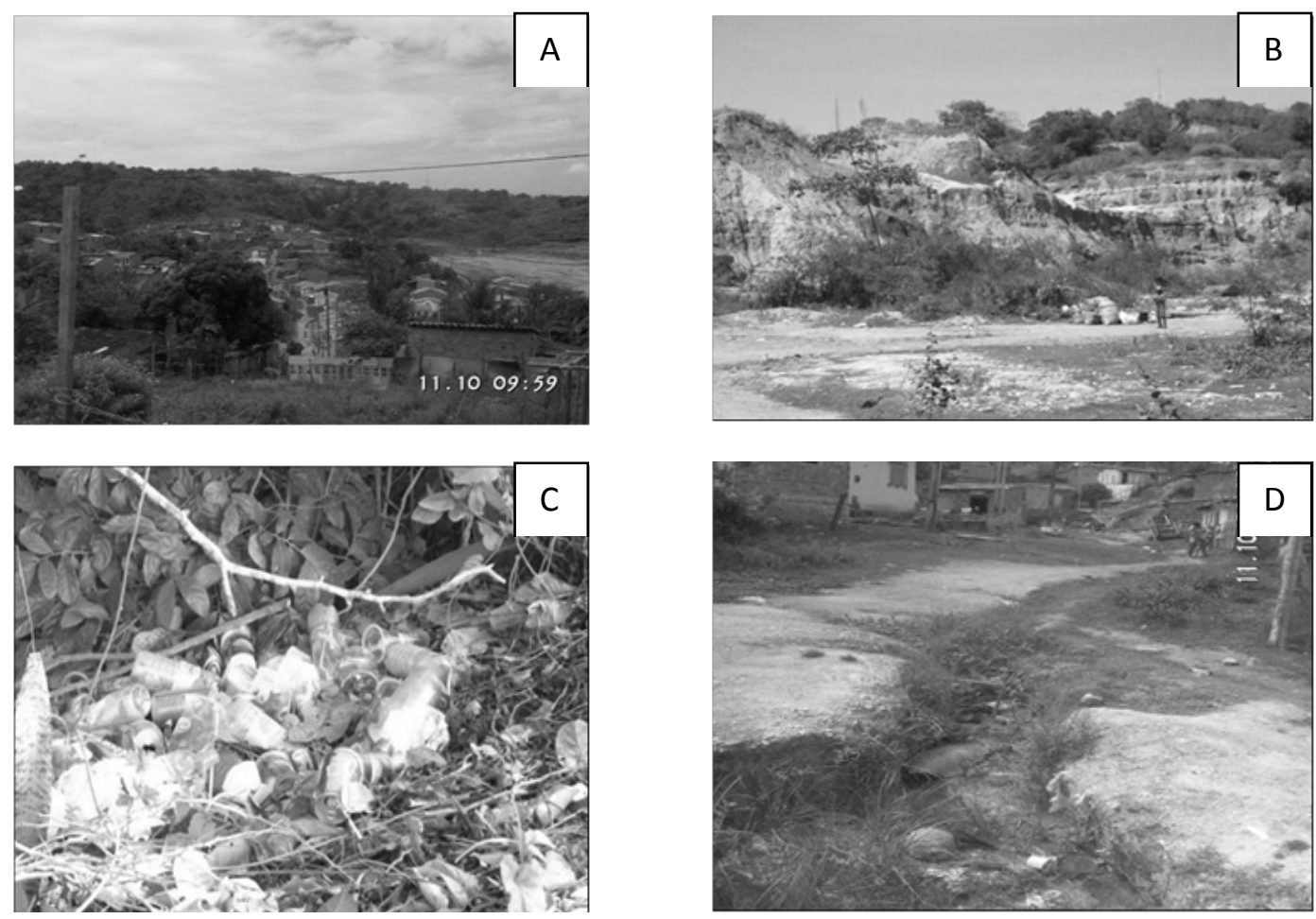

Figura 2 - Impactos ambientais negativos oriundos das atividades da Comunidade Coqueiral no bairro Porto Dantas, Aracaju, Sergipe. 
Segundo Matos (2010), em se tratando de um problema socioambiental, as ocupações subnormais e seu conseqüente impacto ambiental constituem-se como reflexo de algumas camadas sociais de menor poder aquisitivo, que ocupam áreas sem qualquer tipo de infra-estrutura urbana, ordenamento territorial ou mesmo a titularidade da área ocupada, constituindo dessa forma assentos subnormais conhecidos popularmente por favela. Em vista da crescente degradação socioambiental que ocorre na área da APA Morro do Urubu, tem sido desenvolvidos trabalhos de Educação Ambiental com a população que reside na APA. Essas ações são de fundamental importância em busca da sustentabilidade nessa Unidade de Conservação.

Para fazer um levantamento das ações de Educação Ambiental na Área de Proteção Ambiental Morro do Urubu, foram realizadas visitas e aplicados questionários a pessoas que atuam diretamente na gestão da APA Morro do Urubu e em Projetos de Educação Ambiental nesta. Os agentes amostrados foram de três instituições diferentes: SEMARH; UFS e CRAS - Coqueiral.

\section{A) SEMARH}

A Secretaria de Meio Ambiente e Recursos Hídricos - SEMARH, é quem detém a administração da Área de Proteção Ambiental Morro do Urubu. Sob a Gestão de biólogo e Analista Ambiental, a Educação Ambiental é trabalhado com os Visitantes do Parque da Cidade; Associação de Moradores da APA; Professores das escolas localizadas na APA; Estudantes das escolas da APA; Faculdades e Universidades do Estado de Sergipe. Os espaços de atuação são Trilhas do Parque da Cidade; Escolas; CRAS Coqueiral e CRAS Porto Dantas.

As atividades de Educação Ambiental que são desenvolvidas pela SEMARH são o Projeto "Quinta no Parque", Visitas Técnicas das Faculdades e Universidades, Parcerias comosEscoteirosdoEstado, Atendimento aosalunos deGraduação, Pós-graduaçãode Faculdades e Universidades. Essas atividades tiveram início a partir de 2006, em média são 20 pessoas por atividade, exceto no evento do dia das crianças e na semana do meio ambiente que chega a assistir até 2.000 pessoas entre crianças, adolescentes e adultos .

Essas atividades desenvolvidas fazem parte do programa institucional da SQS/SEMARH e neste são realizadas oficinas, palestras e enquetes teatrais. As abordagens de Educação Ambiental que estão sendo aplicadas são a Educação Ambiental Convencional; Educação Ambiental Crítica; Educação Ambiental Transformadora; Educação no processo de Gestão Ambiental.

Os resultados dessas ações tem sido positivos pela aprovação da Política Estadual de Educação Ambiental e um aumento da percepção das comunidades inseridas no programa e/ou moradores do entorno da APA, que o local conhecido como Morro do Urubu, é uma área protegida regida por leis federais. As atividades são monitoradas a partir de relatórios mensais na própria SEMARH.

Para o Gestor é fundamental que as intituições e grupos que trabalham com Educação Ambiental na APA Morro do Urubu busquem 
antecipadamente o órgão gestor da referida Unidade de Conservação para uma boa parceria, conhecer de perto a comunidade do entorno da APA, conhecer o conselho consultivo da APA e seu trabalho.

\section{B) CRAS - Coqueiral}

A SEMARH trabalha em conjunto com outros grupos como CRAS - Coqueiral, que desenvolve trabalhos de Educação Ambiental. O questionário foi aplicado com a Assistente Social do CRAS - Coqueiral. O Projeto de Educação Ambiental desenvolvido pelo CRAS - Coqueiral faz parte de um Prograna institucional o PAC-Coqueiral. Desenvolve trabalhos de Agentes Ambientais Multiplicadores com a associação de moradores da APA Morro do Urubu e Estudantes das Escolas da APA. As atividades desenvolvidas na APA são oficinas; cursos; palestras e coleta seletiva. Essas atividades tiveram início em 2008 e as reuniões são realizadas onde houver pessoas.

Inicialmente, o curso de Agentes Ambientais Multiplicadores foi ministrado para uma turma de 150 pessoas, das quais mantiveram-se atuantes apenas 60 pessoas. Os instrumentos metodológicos usados são questionários, entrevistas dentre outros. A abordagen de Educação Ambiental utilizada na APA por esse grupo é a Educação Ambiental Transformadora e a Alfabetização Ecológica. Os resultados alcançados é que foi montada uma associação de catadores; coleta seletiva no Porto Dantas e a Conservação do Morro do Urubu e do manguezal adjacente. A avaliação dessas atividades são monitoradas através de reuniões. A recomendação dada pelo CRAS-Coqueiral é que sejam aumentadas as ações de Educação Ambiental na APA para alcançar maior esclarecimento aos moradores sobre coleta seletiva e melhores condições de fiscalização.

\section{C) UFS - Projeto Sala Verde}

Outro grupo que está desenvolvendo trabalhos de Educação Ambiental na APA é a Universidade Federal de Sergipe, através do Projeto Sala Verde. Foram aplicados questionários a 2 pessoas que estão envolvidas nestes trabalhos. A primeira é bióloga e trabalha com EA há 3 anos e com a APA há 1 ano, num Projeto de pesquisa com financiamento - FAPITEC/CNPQ e Projeto de pesquisa sem financiamento. $\mathrm{O}$ público em que atua na Educação Ambiental são os visitantes do Parque da Cidade e os espaços são as trilhas do Parque da Cidade. Os instrumentos metodológicos ainda serão implementados e a abordagem é a Educação Ambiental Crítica. Os resultados ainda serão coletados. Mas para o bom andamento dessas atividades foram elaborados questionários que foram analisados e estão sendo desenvolvidos trabalhos com as trilhas referentes aos resíduos sólidos. Segundo a biologa foi verificado que existe a necessidade de lidar com a comunidade que vai a APA Morro do Urubu para inserir uma percepção ambiental nessas comunidades.

Ainda na Sala Verde uma Pedagoga foi entrevistada sobre suas atividades na APA Morro do Urubu, que trabalha como bolsista voluntária num Projeto de extensão sem financiamento - UFS. 
Os trabalhos são realizados com os frequentadores e visitantes do Parque da Cidade subdivididos em três públicos alvo principais: crianças, adolescentes e adultos, sendo as atividades direcionadas e adaptadas segundo a faixa etária do visitante. Os trabalhos desenvolvidos são práticas pedagógicas através de oficinas com crianças para que elas possam entender que o Parque da Cidade não é apenas um lugar de recreação. Com os adolescentes foi focada a questão da necessidade de se cuidar dos animais e com os adultos é trabalhado as trilhas e a importância da preservação da natureza. Essas atividades são realizadas em dias em que o Parque da Cidade está movimentado, por isso o público é variado e não tem um quantitativo.

Os procedimentos metodológicos utilizados são questionários, fotografias, ficha de campo etc. A abordagem é a Educação Ambiental Crítica e sua aplicação está em andamento. Há uma dificuldade de monitorar os resultados em vista da rotatividade dos frequentadores da APA, além das dificuldades inerentes ao fato dos moradores demonstrarem resistência em mudar seus hábitos. Estava previsto a realização de monitoramento das atividades para o ano de 2011. Na pesquisa de campo observou-se a necessidade que as pessoas tanto visitantes como moradores tem de se sentirem responsáveis pelo meio ambiente.

Nas abordagens de Educação Ambiental observou-se que cada grupo tem usado um ou vários tipos de abordagens, tendo como destaque a Educação Ambiental Crítica que "objetiva promover ambientes educativos de mobilização dos processos de intervenção sobre a realidade e seus problemas socioambientais, para que sejam superados nestes ambientes as armadilhas dos paradigmas atuais e propiciar um processo educativo, em que nesse exercício, educandos e educadores, se capacitando e contribuindo, pelo exercício de uma cidadania ativa, na transformação da grave crise socioambiental", muito apropriada uma vez que a maior causa dos problemas da APA Morro do Urubu tem sua origem na problemática socioambiental.

\section{IV - Considerações Finais}

A Área de Proteção Ambiental Morro do Urubu é de grande importância para a conservação da biodiversidade, no entanto passa por intenso processo de urbanização o que vem comprometendo seus ecossistemas naturais e consequentemente corroborando para a perda crescente de qualidade ambiental. Foi possível perceber também a resistência de moradores e visitantes do parque em aceitar mudanças de hábitos cotidianos causadores de impactos ambientais negativos, de modo que se tornam imprescindíveis as ações de Educação Ambiental na APA Morro do Urubu.

Várias intituições como discutido anteriormente, tem promovido e aplicado a Educação Ambiental e suas diferentes abordagens na APA Morro do Urubu, com o intuito de diminuir o problema político e socioambiental enfrentado por essa APA. Concernente às abordagens de Educação Ambiental observou-se que cada grupo tem usado um ou vários tipos de abordagens, tendo como destaque a Educação Ambiental Crítica que "objetiva promover ambientes educativos de mobilização dos processos de intervenção sobre a realidade e seus problemas socioambientais, para que sejam superados nesses ambientes as 
armadilhas dos paradigmas atuais e propiciar um processo educativo, em que nesse exercício, educandos e educadores, se capacitando e contribuindo, pelo exercício de uma cidadania ativa, na transformação da grave crise socioambiental", muito apropriada a problemática da APA Morro do Urubu.

Portanto, conclui-se que as Ações de Educação Ambiental na APA Morro do Urubu em Aracaju tem ainda incipientes, pois foi possível identificar na visita aos gestores e frequentadores da área que o maior foco dessas ações é o Parque da Cidade, localizado dentro dos limites da APA Morro do Urubu, sendo que sua área engloba uma grande população que necessita ser sensibilizada quanto a questão ambiental. Contudo, as poucas Ações de Educação Ambiental pelos grupos que foram pesquisados nesse estudo tem sido ativas e eficazes, mas, observou-se que tais grupos precisam de mais apoio pois não têm estrutura para atingir toda a comunidade.

\section{V - Referênciais}

BRASIL. Sistema Nacional de Unidades de Conservação da Natureza - SNUC, lei $\mathrm{n}^{\circ}$ 9.985, de 18 de jul. de 2000; decreto $\mathrm{n}^{\circ} 4.340$, de 22 de ago. de 2002. 5.ed.aum. Brasília: MMA/SBF, 56p, 2004.

BRASIL. Lei no 9.795/99, 27 de abril. Estabelece a Política Nacional de Educação Ambiental. Departamento de Educação Ambiental. Brasília, 27 de abril de 1999.

BUSTOS, Myriam Ruth Lagos. A educação ambiental sob a ótica da gestão dos recursos hídricos/M.R.L.Bustos. -São Paulo, 2003. p 194. Tese (Doutorado)-Escola Politécnica da Universidade de São Paulo. Departamento de Engenharia Hidráulica e Sanitária.

DALLE, S. P.; POTVIN, C. Conservation of useful plants: an evaluation of local priorities from two indigenous communities in eastern Panama. Economic Botany, v. 58, n.1, p.38-57, 2004.

FREY,Klaus. Adimensão política-democráticanasteoriasdedesenvolvimentosustentávelesuasaplicaçõesparaagestãolocal.Ambiente\&Sociedade.AnoIV,n.9,2sem/2001.

GUIMARÃES, Mauro. Identidades da educação ambiental brasileira / Ministério do Meio Ambiente. Diretoria de Educação Ambiental; Philippe Pomier Layrargues (coord.). - Brasília: Ministério do Meio Ambiente, 2004. p 25-34.

GOMES, Laura Jane et al. Unidades de Conservação no Estado de Sergipe. Revista da Fapese, v. 2, n. 1, p. 101-112, jan./jun. 2006.

Instituto Brasileiro de Análises Sociais e Econômicas (Ibase) Linha de Ação: 4.2 Educação Ambiental na Gestão Participativa: fortalecimento do conselho consultivo do Parque Nacional da Tijuca - Projeto Água em Unidade de Conservação, projeto-piloto para a Mata Atlântica: Parque Nacional da Tijuca. 2006. 
LIMA, Gustavo Ferreira da. Identidades da educação ambiental brasileira / Ministério do Meio Ambiente. Diretoria de Educação Ambiental; Philippe Pomier Layrargues (coord.). - Brasília: Ministério do Meio Ambiente, 2004. p. 85-111.

MATOS, Anselmo Araújo. Gestão e percepção ambiental: a Área de Proteção Ambiental Morro do Urubu - Aracaju (SE) / Anselmo Araújo Matos. - São Cristóvão, 2010. 163 f. : il. Dissertação (Mestrado em Desenvolvimento e Meio Ambiente). Universidade Federal de Sergipe, 2010.

MUNHOZ, Déborah. Identidades da educação ambiental brasileira / Ministério do Meio Ambiente. Diretoria de Educação Ambiental; Philippe Pomier Layrargues (coord.). - Brasília: Ministério do Meio Ambiente, 2004. p 141-155.

REIGOTA, M. Meio Ambiente e Representação Social. São Paulo: Cortez, 1995.

ROCHA, D. "Estratégia Empresarial e Gestão Ambiental: Diagnóstico da Indústria Têxtil do Estado do Rio de Janeiro". 1999. Dissertação de Mestrado, Instituto Alberto Liz Coimbra de Pós-Graduação e Pesquisa de Engenharia, Orientador: Nelson Francisco Favilla Ebecken.

SANTOS, Lívia Isabela da Costa. Identificação Dos Impactos Ambientais Na Área De Proteção Ambiental Morro Do Urubu, Aracaju-Se. Monografia. Engenharia Florestal. Universidade Federal de Sergipe. 2009. 65 p.

SCHETTINO, Sofia Cerqueira. A Criação do Parque Nacional da Serra de Itabaiana e a Sustentabilidade nos Povoados - Subprojeto Povoado Mundes. Relatório parcial de atividades do bolsista, 2008.

Secretaria de Meio Ambiente e Recursos Hídricos de Sergipe (SEMARH). Acesso ao site www.semarh.se.gov.br/biodiversidade/module 14/09/2010.

TORRES, Denise de Freitas; Oliveira, Eduardo Silva de. Percepção Ambiental: Instrumento para Educação Ambiental em Unidades De Conservação Rev. eletrônica Mestrado em Educação Ambiental. ISSN 1517-1256, v. 21, julho a dezembro de 2008. 